\title{
Update on Carotid Stenting and Endarterectomy
}

\author{
Puay Yong NG (i) \\ Mt Elizabeth Medical Centre, Singapore \\ Email: puayyongng@yahoo.com
}

How to cite this paper: NG, P.Y. (2021) Update on Carotid Stenting and Endarterectomy. International Journal of Clinical Medicine, 12, 433-440.

https://doi.org/10.4236/ijcm.2021.1210039

Received: September 22, 2021

Accepted: October 17, 2021

Published: October 20, 2021

Copyright $\odot 2021$ by author(s) and Scientific Research Publishing Inc. This work is licensed under the Creative Commons Attribution International License (CC BY 4.0).

http://creativecommons.org/licenses/by/4.0/

\begin{abstract}
The role of carotid stenting and endarterectomy has been evolving over the past few decades. Results of recent randomized trials have added more insights to the indications of the two established interventions for symptomatic moderate to severe stenosis as well as asymptomatic carotid stenosis. Despite a wide range of complication rates in various trials for both symptomatic and asymptomatic carotid stenosis, benefits of the two interventions have been consistently demonstrated for symptomatic moderate stenosis as well as asymptomatic severe stenosis albeit with lower benefit margin for asymptomatic disease. Intervention for asymptomatic carotid stenosis should only be considered when the complication rate can be maintained below $3 \%$.
\end{abstract}

\section{Keywords}

Carotid Stenosis, Stenting

\section{Introduction}

The role of surgical carotid endarterectomy or endovascular stenting for carotid stenosis has been vigorously studied in multiple randomized trials over the past few decades. Results of the recently completed Second Asymptomatic Carotid Atherosclerosis Study (ACST-2) study have shed more light in the management of carotid stenosis [1]. This article represents a point of view from a neutral neurosurgeon who performs both surgery and endovascular treatment for carotid disease.

\section{Main Text}

For asymptomatic carotid stenosis more than $60 \%$ by North American Symptomatic Carotid Endarterectomy Trial (NASCET) [2] [3] criteria, carotid endarterectomy was proven to be superior to best medical therapy by Asymptomatic 
Carotid Atherosclerosis Study (ACAS) [4] and Asymptomatic Carotid Surgery Trial (ACST-1) [5]. In ACAS trial, the aggregate risk of ipsilateral stroke over 5 years and any perioperative stroke or death was $11 \%$ with best medical therapy vs $5.1 \%$ in the surgical arm. For ACST-1, the equivalent event rates were $11.8 \%$ with best medical therapy vs $6.4 \%$ for surgical arm. The differences in outcome were statistically significant for both studies. In the ACST-2 study, which is a randomized trial of carotid endarterectomy vs stenting in severe asymptomatic carotid stenosis greater than $60 \%$ by NASCET criteria, $1 \%$ had disabling stroke or death procedurally (15 allocated to stenting and 18 to endarterectomy) and $2 \%$ had non-disabling procedural stroke (48 allocated to stenting and 29 to endarterectomy). Kaplan-Meier estimates of 5-year non-procedural stroke risks were $2.5 \%$ in each group for fatal or severe disabling stroke, and $5.3 \%$ with stenting versus $4.5 \%$ with endarterectomy for any stroke. The difference was statistically not significant and the study group concluded that "serious complications are similarly uncommon after competent stenting and endarterectomy, and the long term effects of these two carotid artery procedures on fatal or disabling stroke are comparable". The Stenting and Angioplasty with Protection in Patients at High Risk for Endarterectomy (SAPPHIRE) trial compared the role of stenting and endarterectomy in a group of high-risk patients [6] [7]. Patients were eligible for randomization to either endarterectomy surgery or carotid stenting with distal protection if they had at least one coexisting condition believed potentially to increase the risk posed by endarterectomy and if a study surgeon and interventionalist agreed patients could undergo either procedure safely. The inclusion criteria were the presence of one or more criteria for high surgical risk and a stenosis of more than $50 \%$ of the luminal diameter in patients with symptoms or a stenosis of more than $80 \%$ in those without symptoms. The criteria for high surgical risk were clinically significant cardiac disease (congestive heart failure, abnormal stress test or the need for open-heart surgery), severe pulmonary disease, contralateral carotid occlusion, contralateral laryngeal nerve palsy, recurrent stenosis after carotid endarterectomy, previous radical neck surgery or radiation therapy to the neck or age of more than 80 years. Stenting was performed with the use of a self-expanding, nitinol stent (Smart or Precise, Cordis, USA) and an emboli-protection device (Angioguard or Angioguard XP Embolic Capture Guidewire, Cordis, USA). The 30-day major event (stroke, myocardia infarct or death) rate was $5.8 \%$ for the stenting group compared with $12.6 \%$ in the endarterectomy group. The durability of carotid stenting was also shown in this study. At 3 years follow-up, results showed that the prespecified end point (stroke, myocardia infarct or death) occurred in 41 patients in the stenting group (cumulative incidence, 24.6\%; Kaplan-Meier estimate, 26.2\%) and 45 patients in the endarterectomy group (cumulative incidence, 26.9\%; Kaplan-Meier estimate, $30.3 \%)$. The investigators concluded that stenting was not inferior to endarterectomy and that no significant difference could be shown in the long-term outcomes between the two procedures. 
Taken together, these four landmark randomized trials showed that there are two equally effective treatment options for asymptomatic severe carotid stenosis ( $>60 \%$ by NASCET criteria) if the periprocedural complication rate can be maintained below 3\%, when the patient has a life expectancy of over 5 years.

The role of carotid endarterectomy in symptomatic carotid stenosis has been well established by randomised control trials. In patients with symptomatic atherosclerotic carotid stenosis greater than $70 \%$ by NASCET criteria, the value of endarterectomy was established by the results of NASCET and the European Carotid Surgery Trial (ECST) [8]. In NASCET, the estimate of any ipsilateral stroke at 2 years for patients with symptomatic high grade stenosis was $26 \%$ in the medical arm and $9 \%$ in the surgical arm. For symptomatic carotid stenosis in the moderate category (50\% to $69 \%$ stenosis), NASCET and ECST demonstrated significant benefits for endarterectomy compared to best medical therapy. In NASCET, the 5-year risk of ipsilateral stroke over the 5-year follow period was $22.2 \%$ in the medically treated group compared to $15.7 \%$ in patients treated surgically. The surgical complication rate was kept below $6 \%$ in these trials. For patients with carotid stenosis below $50 \%$ by NASCET criteria, these trials showed that there was no significant benefit with surgery.

The first major randomised control trial for direct comparison of endarterectomy versus stenting was the Carotid and Vertebral Artery Transluminal Angioplasty Study (CAVATAS) [9]. In this study, three-quarters of the cases in endovascular group received balloon angioplasty alone without stenting. The rates of major outcome events within 30 days of first treatment did not differ significantly between endovascular treatment and surgery (6.4\% vs $5.9 \%$, respectively, for disabling stroke or death; $10.0 \%$ vs $9.9 \%$ for any stroke lasting more than 7 days, or death). Cranial neuropathy was reported in 22 (8.7\%) surgery patients, but not after endovascular treatment $(\mathrm{p}<0.0001)$. Major groin or neck haematoma occurred less often after endovascular treatment than after surgery $(1.2 \%$ vs $6.7 \%, \mathrm{p}<0.0015)$. At 1 year after treatment, severe $(70 \%-99 \%)$ ipsilateral carotid stenosis was more common after endovascular treatment ( $14 \%$ vs $4 \%, \mathrm{p}<$ 0.001). However, no substantial difference in the rate of ipsilateral stroke was noted with survival analysis up to 3 years after randomization. The investigators concluded that endovascular treatment had similar risks and effectiveness at prevention of stroke at three years compared with endarterectomy. They also concluded that there was a wide confidence interval and endovascular treatment had the advantage of avoiding minor complications. After the results were published the study was criticised for having too high a complication rate for the surgical arm and too much variation in the endovascular treatment arm in terms of acceptable techniques including with or without stenting or the use of distal protection. In the long term follow up study of the CAVATAS cohort the estimated cumulative 8-year incidence of non-perioperative ipsilateral stroke was $11.3 \%$ in the endovascular group and $8.6 \%$ in the endarterectomy group [10]. The overall risk difference was not significant when the data were analysed by intention-to- 
treat or by treatment received.

Subsequent randomized control trials comparing endarterectomy vs stenting were more stringent in terms of requirements for operator experience as well as the devices used in the treatment arms. The Stent-Supported Percutaneous Angioplasty of the Carotid Artery versus Endarterectomy (SPACE) [11] trial compared stenting vs endarterectomy for patients with symptomatic carotid stenosis greater than $70 \%$ by NASCET criteria. For SPACE trial, surgeons must submit results for 25 consecutive endarterectomy procedures. Interventionist must have performed a minimum of 25 stenting or angioplasty procedures. Use of protection devices, predilation, and balloon was at the discretion of the interventional physician. In both the intention-to-treat and per-protocol analyses the KaplanMeier estimates of ipsilateral ischaemic strokes up to 2 years after the procedure and any periprocedural stroke or death did not differ between the carotid artery stenting and the carotid endarterectomy groups (intention to treat $9.5 \%$ vs $8.8 \%$; $\mathrm{p}=0.31$ ). The investigators further reported that the incidence of recurrent carotid stenosis at 2 years, as defined by ultrasound, was significantly higher after carotid artery stenting. However, it could not be excluded that the degree of instent stenosis was slightly overestimated by conventional ultrasound criteria. In the Endarterectomy Versus Angioplasty in Patients with Symptomatic Severe Carotid Stenosis (EVA-3S) trial, the 30-day incidence of any stroke or death was $3.9 \%$ after endarterectomy and $9.6 \%$ after stenting [12] [13]. The 30-day incidence of stroke or deaths was $25 \%$ for stenting without distal protection compared with $7.9 \%$ with protection device. In fact, the study was temporarily stopped at one stage due to the excessive complication rate of stenting without distal protection. It is worth mentioning that in the EVA-3S trial, stents could be placed by physicians who had performed as few as five previous carotid-stent procedures or, if working under the direction of a tutor, with no previous procedural experience. There were five different stents and seven different distal protection devices used in various stages of the study. The cumulative probability of periprocedural stroke or death and non-procedural ipsilateral stroke after four years of follow-up was higher with stenting than with endarterectomy (11.1\% vs 6.2\%). A hazard function analysis showed that the 4-year differences in the cumulative probabilities of outcomes between stenting and endarterectomy were largely accounted for by the higher periprocedural (within 30 days of the procedure) risk of stenting compared with endarterectomy. After the periprocedural period, the risk of ipsilateral stroke was low and similar in both treatment groups. The cumulative probability of any ipsilateral stroke or procedural stroke/death at 5 years occurred in $11.0 \%$ of the stenting group vs. $6.3 \%$ of the endarterectomy group ( $\mathrm{p}=0.04$ ), whereas the cumulative probability of any ipsilateral stroke or procedural stroke/death at 10 years occurred in $11.5 \%$ of the CAS group vs. $7.6 \%$ of the CEA group $(\mathrm{p}=0.07)$. The trial investigators concluded that at 5 years of follow-up, there was an excess of any ipsilateral stroke or procedural stroke/ death with stenting compared to endarterectomy. At 10 years, adverse events were 
still numerically higher with stenting; however, the difference was nonsignificant. Postprocedural ipsilateral strokes were infrequent and occurred at a similar frequency between groups. On the contrary, in the SAPPHIRE trial, where high risk patients were randomized for stenting or endarterectomy, stenting was found not to be inferior to endarterectomy and that no significant difference could be shown in the long term outcomes between the two carotid interventional procedures. It is worth noting that in the SAPPHIRE trial, the selection of interventionist or surgeon was stringent. Surgical investigators had a median annual volume of 30 endarterectomies (range, 15 to 100). Because carotid-artery stenting was a relatively new procedure then, the total experience of interventional physicians with this procedure (median, 64 procedures; range, 20 to 700), instead of the annual volume, was reviewed by the study committee. In addition, only selfexpanding, nitinol stent (Smart or Precise, Cordis, USA) and an emboli-protection device (Angioguard or Angioguard XP Embolic Capture Guidewire, Cordis, USA) was allowed. In the Carotid Revascularization Endarterectomy vs Stenting Trial (CREST), where the outcomes of stenting with those of carotid endarterectomy among patients with symptomatic or asymptomatic extracranial carotid stenosis were compared, it was reported that for 2502 patients over a median follow-up period of 2.5 years, there was no significant difference in the estimated 4 -year rates of the primary end point between the stenting group and the endarterectomy group $(7.2 \%$ and $6.8 \%, \mathrm{P}=0.51)$ [14]. The investigators further concluded that among patients with symptomatic or asymptomatic carotid stenosis, the risk of the composite primary outcome of stroke, myocardial infarction, or death did not differ significantly in the group undergoing stenting and the group undergoing endarterectomy. During the periprocedural period, there was a higher risk of stroke with stenting and a higher risk of myocardial infarction with endarterectomy. This trial was very stringent in the selection of surgeons for endarterectomy and interventionist for stenting. Certification was achieved by 477 surgeons, whose clinical results were audited by means of a validated selection process documenting that they performed more than 12 procedures per year and that the rates of complications and death were less than $3 \%$ among asymptomatic patients and less than 5\% among symptomatic patients. The 224 interventionists were certified after satisfactory evaluation of their endovascular experience, carotid-stenting results, participation in hands-on training, and participation in a lead-in phase of training. For carotid-artery stenting, the protocol specified use of the RX Acculink stent (Abbott Vascular Solutions, IL, USA) and, whenever feasible, the RX Accunet embolic-protection device (Abbott Vascular Solutions, IL, USA). In the International Carotid Stenting Study (ICSS) the number of fatal or disabling strokes as well as cumulative 5 -year risk did not differ significantly between the stenting and endarterectomy groups (6.4\% vs $6.5 \% ; \mathrm{p}=0.77)$ [15]. The investigators concluded that the long-term functional outcome and risk of fatal or disabling stroke are similar for stenting and endarterectomy for symptomatic carotid stenosis greater than $50 \%$. 
There have also been meta-analyses published based on the randomized trials and the conclusion appears to favour endarterectomy with a slightly higher complication risk of non-disabling strokes associated with carotid stenting [16]. The limitations of meta-analysis are well known. One of the major drawbacks of endovascular stenting is the myriad distal protection devices as well as stents used for the revascularisation procedures. Over the years various distal protection devices such as distal balloons, proximal or flow reversal protection balloons, filter wires, etc, have been developed with variable results. Different types of stents including balloon mounted stents, self-expanding stents, closed cell stents, open cell stents, tapered stents and even covered stents have been used at various stages in the past. Therefore, the results of the separate trials with or without distal protection devices as well as different devices may not be comparable. It appears that with prior training and the use of specific distal protection devices and stents as in SAPPHIRE and CREST trials, complications with carotid stenting could be reduced and no significant difference could be detected in long term follow up studies comparing stenting vs endarterectomy.

Without going into complex statistical analysis, it is obvious that in objective randomized clinical trial settings, the long-term outcome for carotid endarterectomy or stenting is similar and ranged roughly from around 3\% to $12 \%$ for composite event rates of disabling stroke, myocardial infarction or death. Some of the trials mentioned above included over thousand cases with follow up long term to ten years. With a large enough sample size, the treatment arm with a lower complication rate will emerge as the better treatment option. There will always be criticisms for any randomized trial designs. The proponents of either treatment options will not be satisfied when the results go against their expectation. No one can deny the fact that both therapeutic options require proper training and experience to achieve low complication rates. There are as many nuances in carotid stenting as in endarterectomy to avoid perioperative morbidities.

\section{Conclusion}

In conclusion, randomized trials so far support both endarterectomy and stenting as effective treatments for symptomatic carotid stenosis above $50 \%$ and asymptomatic stenosis above $60 \%$ if the perioperative complication rate can be maintained at a low level. Intervention for asymptomatic carotid stenosis should only be considered when the complication rate can be maintained below $3 \%$.

\section{Conflicts of Interest}

The author declares no conflicts of interest regarding the publication of this paper.

\section{References}

[1] Halliday, A., Bulbulia, R., Bonati, L., Chester, J., Cradduck-Bamford, A., Peto, R., Pan, H., et al. (2021) Second Asymptomatic Carotid Surgery Trial (ACST-2): A Randomised Comparison of Carotid Artery Stenting versus Carotid Endarterectomy. The Lancet, 398, 1065-1073. https://doi.org/10.1016/S0140-6736(21)01910-3 
[2] North American Symptomatic Carotid Endarterectomy Trial Collaborators (1991) Beneficial Effect of Carotid Endarterectomy in Symptomatic Patients with HighGrade Carotid Stenosis. The New England Journal of Medicine, 325, 445-453. https://doi.org/10.1056/NEJM199108153250701

[3] Ferguson, G.G., Eliasziw, M., Barr, H.W., Clagett, G.P., Barnes, R.W., Wallace, M.C., Taylor, D.W., Haynes, R.B., Finan, J.W., Hachinski, V.C. and Barnett, H.J. (1999) The North American Symptomatic Carotid Endarterectomy Trial: Surgical Results in 1415 Patients. Stroke, 30, 1751-1758.

https://doi.org/10.1161/01.STR.30.9.1751

[4] Executive Committee for the Asymptomatic Carotid Atherosclerosis (1995) Endarterectomy for Asymptomatic Carotid Artery Stenosis Study. JAMA, 273, 1421-1428.

[5] Halliday, A., Harrison, M., Hayter, E., Kong, X., Mansfield, A., Marro, J., Pan, H., Peto, R., Potter, J., Rahimi, K., Rau, A., Robertson, S., Streifler, J., Thomas, D. and Asymptomatic Carotid Surgery Trial (ACST) Collaborative Group (2010) 10-Year Stroke Prevention after Successful Carotid Endarterectomy for Asymptomatic Stenosis (ACST-1): A Multicentre Randomised Trial. The Lancet, 376, 1074-1084. https://doi.org/10.1016/S0140-6736(10)61197-X

[6] Yadav, J.S., Wholey, M.H., Kuntz, R.E., Fayad, P., Katzen, B.T., Mishkel, G.J., Bajwa T.K., Whitlow, P., Strickman, N.E., Jaff, M.R., Popma, J.J., Snead, D.B., Cutlip, D.E., Firth, B.G., Ouriel, K., et al. (2004) Protected Carotid-Artery Stenting versus Endarterectomy in High-Risk Patients. The New England Journal of Medicine, 351, 1493-1501. https://doi.org/10.1056/NEJMoa040127

[7] Gurm, H.S., Yadav, J.S., Fayad, P., Katzen, B.T., Mishkel, G.J., Bajwa, T.K., Ansel, G., Strickman, N.E., Wang, H., Cohen, S.A., Massaro, J.M., Cutlip, D.E., et al. (2008) Long-Term Results of Carotid Stenting versus Endarterectomy in High-Risk Patients. The New England Journal of Medicine, 358, 1572-1579. https://doi.org/10.1056/NEJMoa0708028

[8] European Carotid Surgery Trialists' Collaborative Group (1998) Randomised Trial of Endarterectomy for Recently Symptomatic Carotid Stenosis: Final Results of the MRC European Carotid Surgery Trial (ECST). The Lancet, 351, 1379-1387. https://doi.org/10.1016/S0140-6736(97)09292-1

[9] CAVATAS Investigators (2001) Endovascular versus Surgical Treatment in Patients with Carotid Stenosis in the Carotid and Vertebral Artery Transluminal Angioplasty Study (CAVATAS): A Randomised Trial. The Lancet, 357, 1729-1737. https://doi.org/10.1016/S0140-6736(00)04893-5

[10] Ederle, J., Bonati, L.H., Dobson, J., Featherstone, R.L., Gaines, P.A., Beard, J.D., Venables, G.S., Markus, H.S., Clifton, A., Sandercock, P., Brown, M.M., et al. (2009) Endovascular Treatment with Angioplasty or Stenting versus Endarterectomy in Patients with Carotid Artery Stenosis in the Carotid and Vertebral Artery Transluminal Angioplasty Study (CAVATAS): Long-Term Follow-Up of a Randomised Trial. The Lancet Neurology, 8, 898-907. https://doi.org/10.1016/S1474-4422(09)70228-5

[11] Eckstein, H.H., Ringleb, P., Allenberg, J.R., Berger, J., Fraedrich, G., Hacke, W., Hennerici, M., Stingele, R., Fiehler, J., Zeumer, H. and Jansen, O. (2008) Results of the Stent-Protected Angioplasty versus Carotid Endarterectomy (SPACE) Study to Treat Symptomatic Stenoses at 2 Years: A Multinational, Prospective, Randomised trial. The Lancet Neurology, 7, 893-902. https://doi.org/10.1016/S1474-4422(08)70196-0

[12] Mas, J.L., Chatellier, G., Beyssen, B., Branchereau, A., Moulin, T., Becquemin, J.P., Larrue, V., Lièvre, M., Leys, D., Bonneville, J.F., Watelet, J., Pruvo, J.P., Albucher, J.F., Viguier, A., Piquet, P., Garnier, P., Viader, F., Touzé, E., Giroud, M., Hosseini, 
H., Pillet, J.C., Favrole, P., Neau, J.P., Ducrocq, X., et al. (2006) Endarterectomy versus Stenting in Patients with Symptomatic Severe Carotid Stenosis. The New England Journal of Medicine, 355, 1660-1671. https://doi.org/10.1056/NEJMoa061752

[13] Mas, J.L., Trinquart, L., Leys, D., Albucher, J.F., Rousseau, H., Viguier, A., Bossavy, J.P., Denis, B., Piquet, P., Garnier, P., Viader, F., Touzé, E., Julia, P., Giroud, M., Krause, D., Hosseini, H., Becquemin, J.P., Hinzelin, G., Houdart, E., Hénon, H., Neau, J.P., Bracard, S., Onnient, Y., Padovani, R., Chatellier, G., et al. (2008) Endarterectomy versus Angioplasty in Patients with Symptomatic Severe Carotid Stenosis (EVA-3S) Trial: Results up to 4 Years from a Randomised, Multicentre Trial. The Lancet Neurology, 7, 885-892. https://doi.org/10.1016/S1474-4422(08)70195-9

[14] Mantese, V.A., Timaran, C.H., Chiu, D., Begg, R.J., Brott, T.G., et al. (2010) The Carotid Revascularization Endarterectomy versus Stenting Trial (CREST): Stenting versus Carotid Endarterectomy for Carotid Disease. Stroke, 41, S31-S34.

https://doi.org/10.1161/STROKEAHA.110.595330

[15] Bonati, L.H., Dobson, J., Featherstone, R.L., Ederle, J., van der Worp, H.B., de Borst, G.J., Mali, W.P., Beard, J.D., Cleveland, T., Engelter, S.T., Lyrer, P.A., Ford, G.A., Dorman, P.J., Brown, M.M., et al. (2015) Long-Term Outcomes after Stenting versus Endarterectomy for Treatment of Symptomatic Carotid Stenosis: The International Carotid Stenting Study (ICSS) Randomised Trial. The Lancet, 385, 529-538. https://doi.org/10.1016/S0140-6736(14)61184-3

[16] Müller, M.D., Lyrer, P., Brown, M.M. and Bonati, L.H. (2020) Carotid Artery Stenting versus Endarterectomy for Treatment of Carotid Artery Stenosis. Cochrane Database of Systematic Reviews, 25, Article ID: CD000515. https://doi.org/10.1002/14651858.CD000515.pub5 